OPEN ACCESS

Edited by:

Zhi-Hua Li,

Shandong University, China

Reviewed by:

Chao Wang,

Chinese Academy of Fishery Sciences (CAFS), China

Chuanxin Qin,

Chinese Academy of Fishery

Sciences (CAFS), China

${ }^{*}$ Correspondence:

Di-an Fang

fangda@ffrc.cn

Dong-po Xu

xudp@ffrc.cn

${ }^{\dagger}$ These authors have contributed equally to this work

Specialty section:

This article was submitted to Marine Pollution, a section of the journal Frontiers in Marine Science

Received: 07 October 2021 Accepted: 07 December 2021

Published: 21 January 2022

Citation:

Fang $D$-a, Zhou Y-f, Ren $P$, Peng $Y-x$, Xue $X-p$, Ren $L$ and $X u D-p$ (2022) The Status of Silver Carp Resources and Their Complementary Mechanism in the Yangtze River.

Front. Mar. Sci. 8:790614. doi: 10.3389/fmars.2021.790614

\section{The Status of Silver Carp Resources and Their Complementary Mechanism in the Yangtze River}

\author{
Di-an Fang ${ }^{1,2 * t}$, Yan-feng Zhou't1, Peng Ren ${ }^{1+}$, Yun-xing Peng' ${ }^{2}$ Xiang-ping Xue', \\ Long Ren ${ }^{1}$ and Dong-po $\mathrm{Xu}^{1,2 *}$
}

' Key Laboratory of Freshwater Fisheries and Germplasm Resources Utilization, Ministry of Agriculture and Rural Affairs, Freshwater Fisheries Research Center, Chinese Academy of Fishery Sciences, Wuxi, China, ${ }^{2}$ Wuxi Fisheries College, Nanjing Agricultural University, Wuxi, China

The global climate and environmental variability can induce fish adaptive strategy change and form a corresponding complementary mechanism subsequently. Because of climate fluctuation, human activities, and water conservancy projects, it has been reported that natural fish resources of the silver carp have been declining in a wavy trend from 1950. However, few studies have explored the potential effects of determining the relationship between the adult fish and fish larvae. Using the field survey method, this study analyzed the fisheries resource status of the adult silver carp and its early life stage in the Yangtze River. Results indicated that different geographic populations showed significant habitat dependence, and the adult silver carp tends to choose habitats with slow water flow, rich biological bait, and less human interference. What is more, its distribution pattern has regional and seasonal differences obviously. Additionally, redundancy analysis on the fish larvae showed that water temperature and water flow are the two most important factors influencing the fish larvae blooming. According to the generalized additive model (GAM), the hydrological factors that significantly influence the larvae abundance are water temperature, transparency, daily increasing rate of water level, and discharge $(p<0.05)$. Combining the historical and present research data, the results indicated that river and lake connected habitat is essential for the silver carp recruitment and migration. Future studies should focus on the complementary mechanism of silver carp both in the natural habitat and invasion waters. It is suggested that the spawning habitat should be well protected during the channel project and economic belt construction along the Yangtze River.

Keywords: Hypophthalmichthys molitrix, complementary mechanism, the Yangtze River, climate change, habitat selection, fish larvae

\section{INTRODUCTION}

The most significant change in the global climate and environment is global warming (Zandalinas et al., 2021). A global hydrological water temperature modeling framework predicts the global daily river discharge and water temperature under future climate conditions (van Vliet et al., 2013; Huang et al., 2021). The results showed that the global mean river water temperatures are predicted to increase $0.8-1.6^{\circ} \mathrm{C}$, and the future mean water temperature increase in the Yangtze River is expected 
to be up to $1.8^{\circ} \mathrm{C}$ for the period 2071-2100 (RodriguezDominguez et al., 2019; Yue et al., 2021). Global warming is a critical concern in spawning ecology of fishes, especially in freshwater (Huang et al., 2021). Researchers have indicated that elevated temperatures shorten the spawning period of silver carp in the Pearl River (Shuai et al., 2018). Consequently, global warming is expected to impact the reproductive function of fish, which has implications for wild population dynamics and diversity (Rodriguez-Dominguez et al., 2019). The Yangtze River is the longest river in China, which has an elevation varying from 5,000 to $0 \mathrm{~m}$ above the sea level. High drop and altitude difference lead to different characteristics of water temperature distribution in the Yangtze River (Chen et al., 2020). Because discrete ecosystem in rivers limited fish to follow optimal temperature conditions for spawning migration, the impact of warming was likely to be stronger and stronger especially for fish species in freshwater (Schmidt et al., 2020).

Fish spawning migration patterns are regulated by essential factors such as hydrographic parameters and spawning population stocks (Song et al., 2019). It is well known that construction and operation of the Three Gorges Dam (TGD) have brought changes to the hydraulics and water quality in the middle and lower reach of the Yangtze River (Liu et al., 2019). Consequently, spawning habitats for these fish species have been deteriorated, and thus their populations, such as the silver carp, have decreased (Zhang et al., 2021). Silver carp (Hypophthalmichthys molitrix) is one of the four majorly farmed carps in China (Li et al., 1984), which is a native fish species in the Yangtze River and its resource dynamics can serve as an indicator for the ecosystem (Fu et al., 2003). The Yangtze River is the main place where the germplasm resources have occurred for the silver carp in China (Fu et al., 2003; Fang et al., 2021). According to field surveys, the percentage of the silver carp both in the larval catch and the adult catch has sharply reduced from the 1960s (Wang et al., 2019). Silver carp was artificially bred in 1958 successfully and transported to other countries overboard. Some of them have formed new local populations because of changes in habitat such as water temperature, water flow, and river dynamics. Since 2011, the TGD has been discharging water to make artificial floods into the downstream areas and induced the spawning of four major Chinese carps successfully (Tao et al., 2017).

Fishes cannot live without water, and therefore they are directly affected by the ongoing changes in the aquatic ecosystems. Sexual maturation and successful reproduction are the key processes for species survival and evolution (Servili et al., 2020). In fish, it is largely dependent on specific environmental factors that control or modulate sexual maturation and spawning (Servili et al., 2020). Thus, the ongoing rapid environmental changes directly interfere with reproductive processes and may jeopardize spawning success and fish larvae survival (Rogers et al., 2019). It is well known that dam construction can reduce connectivity of rivers, fragment watersheds, affect fish assemblages by interrupting fish migration, and reduce species diversity (Fu et al., 2003). It also causes direct changes in water depth (WD), flow velocity, and hydrological processes, which result in downstream river channel erosion, physical habitat unfitness, and water quality deterioration. The artificial embankments and dams on surrounding habitats also have resulted in a significant disturbance for the river ecosystem (Addy and Wilkinson, 2021).

As the silver carp resource of Chinese indigenous population showed a declining trend, the strategy of 10-year fishing ban on the Yangtze River has been implemented from January 2020 (Chen et al., 2020). Fish in the early life history refers to the period from fertilization to embryonic and larval stages and then to juvenile stage. It has been proven that the early resources of silver carp in the Yangtze River are under enormous threat (Liu et al., 2004). Overfishing is the most direct reason for the decline in fishery resources, which not only damages the diversity of fish but also destroys the resources of parent fish and juvenile fish, which makes the fish community smaller and younger (Sokta et al., 2020). Large scales of water conservancy construction also have a significant impact on the river ecosystem. It locked the migration pathway and destroyed the spawning grounds and nursery grounds of fish (Yao et al., 2015). Besides, land reclamation and water pollution also lead to the destruction of fish habitat and directly reduced the fish resources (Chen et al., 2017). At present, because of the 10-year strategy of banning fishing, it is necessary to assess the natural process of fish survival, growth, and reproduction both in the adult and larval stages. In this study, we described the major findings of a long-term research program on the fisheries resources survey of the silver carp and provided its possible complementary mechanism in the Yangtze River. Addressing the historical data, the current status of silver carps, the complementary mechanism, and possible management strategies were discussed for encountering the changing climate.

\section{MATERIALS AND METHODS}

\section{Field Sampling Site}

The sampled river section is alongside the lower reach of the Yangtze River. The survey period is from 2016 to 2019. Sampling and study area were in four sections, namely, Hukou (HK), Anqing (AQ), Dangtu (DT), and Changshu (CS). Three sampling sites were set in each section for the larval fish, namely, the right bank (R), the left bank (L), and the middle site (M). Two survey sites were set in each section for the adult fish of silver carp survey (shown in magnified graph, Figure 1).

\section{Adult Fish Survey}

Environmental factors were tested in each sampling site including the following content. Water temperature (WT, ${ }^{\circ} \mathrm{C}$ ), dissolved oxygen (DO, $\left.\mathrm{mg} \cdot \mathrm{L}^{-1}\right)$, and $\mathrm{pH}$ were recorded using a multiparametric probe (WTW Multi 340i, MultiLine, Germany). Water transparency (WTP) was measured using a secchi disk. Current velocity $\left(\mathrm{CV}, \mathrm{m} \cdot \mathrm{s}^{-1}\right)$ was measured using a flow meter Digital Flow Meter 23090 (KC Denmark A/S, Silkeborg, Denmark). Average WD (m) was measured using a depth sounder (S48-1X, Maikeyi, Beijing, China).

The fishing net includes stick-nets and multi-mesh gill nets. Among them, the length of a single stick-net is $75 \mathrm{~m}$, the height of the net is $5 \mathrm{~m}$, the mesh size of the block net is $3.5 \mathrm{~cm}$, and the capsule mesh size of the bag net is $1 \mathrm{~cm}$. The length and height of a single multi-mesh gill net are 100 and $2 \mathrm{~m}$, and 


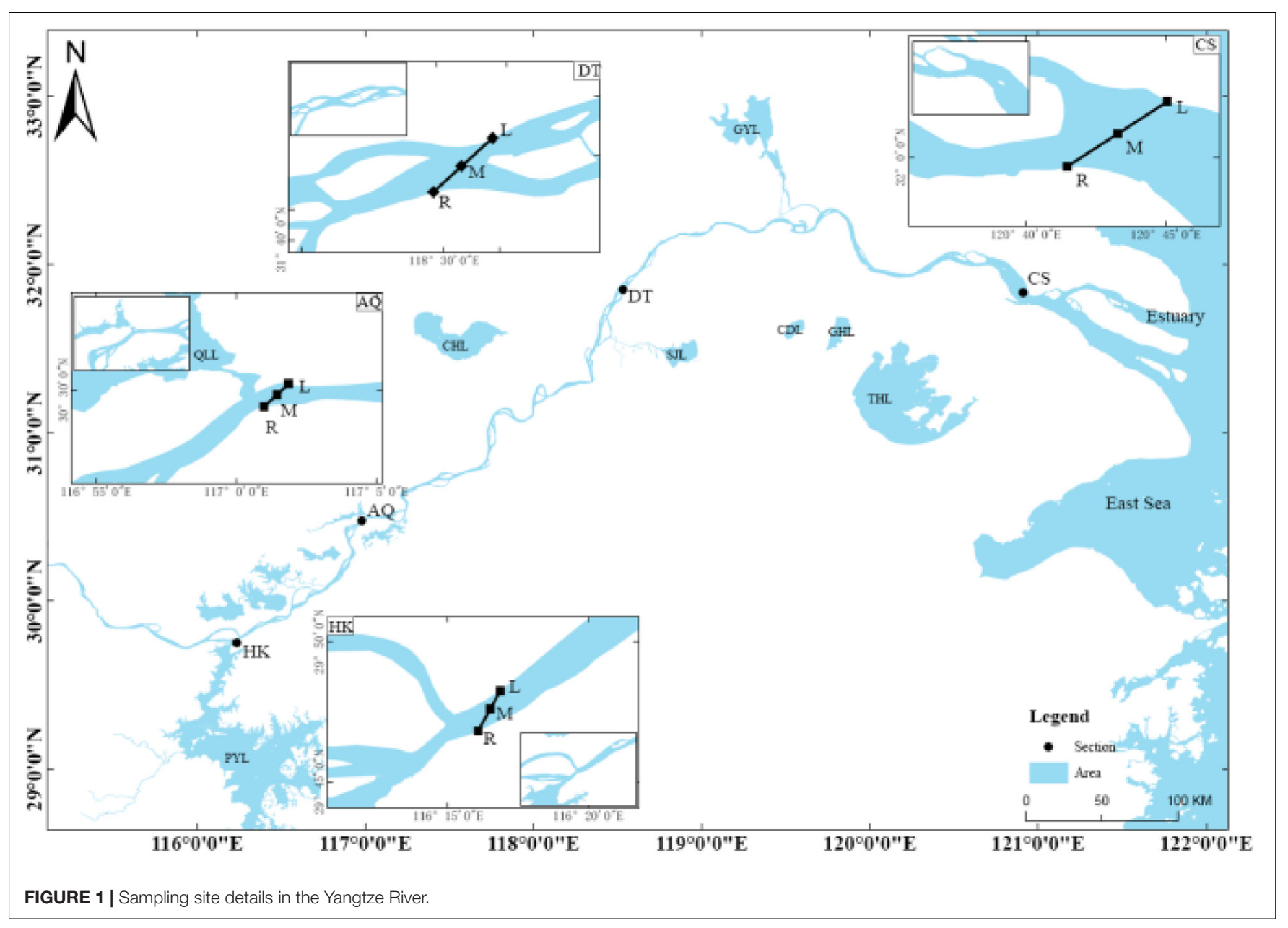

the mesh sizes are $2,4,6,8,10$, and $14 \mathrm{~cm}$, respectively. The investigation period was from January 2016 to December 2019; during the investigation, the multi-mesh gill nets were lowered to the designated investigation waters before 5:00 p.m., and the nets were closed before 8:00 a.m. on the next day. For each catch, the body length (BL) and weight were measured, and the biological characteristics were determined for the sampled sliver carp.

\section{Fish Resource Estimation}

According to the annual average catch per unit effort (CPUE), the total number of fishing vessels and the annual fishing days of a single vessel, the proportion of weight and individual number in each section, and the average annual catch weight and numbers were estimated. Annual average natural resources in the sampled sections were estimated using FISAT II medium length stock analysis method. Among them, the limit BL is $L \infty=1,047.2$ $\mathrm{mm}$ and $k=0.1603$, and the relationship between $\mathrm{BL}$ and body weight is $W=a L^{b}\left(a=0.000040413, b=2.7546 ; R^{2}=0.8652\right)$. The natural mortality estimation module was used in FISAT II and Pauley empirical formula was used to estimate the natural mortality of silver carp (Wang et al., 2019). The fishing mortality coefficient (FMC) of the maximum BL group is 0.5 as the initial value, do repeat calculation using iterative method, until the given
FMC value and the weighted average value of the fishing death coefficient of each BL group converge, then the final FMC value can be determined.

\section{Larval Fish Survey}

Sampling was conducted daily during the fish spawning season. Sampling sites were set to ensure that they typified the four designated sections in terms of the larval fish development (Cao et al., 2007). The sampling process has been described as follows (Ren et al., 2016). Briefly, larval fish were collected using an ichthyologic trap net $\left(0.5 \mathrm{~mm}\right.$ mesh size and $4.9 \mathrm{~m}^{2}$ area of the net mouth). A flow meter (Digital Flow Meter 23090, Denmark) was tied in the net mouth to measure the water flow volume. The sampling process was conducted for about $5 \mathrm{~min}$ on the spot using a traditional fishing boat against the current. Sampling time was set at every morning (08:00-11:00 a.m.) during the fish spawning season (May-August) during 2016-2019. The net was deployed about $20 \mathrm{~m}$ along the river bank side of the sampling sections. Larval fish sampling was conducted upstream using a traditional fish boat at a speed of $2 \mathrm{~km} / \mathrm{h}$. For each sample, after cleaning vegetation and foreign matters, ichthyoplankton were collected and then preserved in 75\% ethanol for later classification and identification. At all sampling sections, WT, 
TABLE 1 | Catch statistics of the sliver carp in each section.

\begin{tabular}{|c|c|c|c|c|c|c|}
\hline Sections & CPUE (Kg) & Fishing boats & Capture days & Annual catch weight (kg) & Annual catch number (tail) & The body length range $(\mathrm{cm})$ \\
\hline HK & 18.31 & 118 & 180 & 4088.29 & 22,372 & $1.2-66.8$ \\
\hline$A Q$ & 12.92 & 126 & 180 & 2213.71 & 11,888 & $1.1-58.2$ \\
\hline DT & 10.84 & 180 & 180 & 4145.62 & 23,616 & $2.3-76.2$ \\
\hline CS & 7.78 & 293 & 180 & 5124.67 & 26,723 & $2.6-87.6$ \\
\hline
\end{tabular}

CPUE, catch per unit effort; HK, Hukou; AQ, Anqing; DT, Dangtu; CS, Changshu.

WF, and WTP were simultaneously measured, respectively. Daily water level and discharge were acquired from the Changjiang Hydrological Network. ${ }^{1}$

\section{Early Resource Occurrence Quantity}

The calculation method of larval fish density refers to the previous method (Cheng et al., 2013; Ren et al., 2016). According to the number of fish larvae collected, the sampling time, the difference between the beginning and end of the flow meter, and the active net area are calculated according to the following formula: $Q_{i}=\left(0.3 \times C i \times a_{i}\right) / t_{i}, D_{i}=\frac{N_{i}}{Q_{i} \times t_{i}}$, where $Q i$ is the flow through the net mouth during the $i$ time period $\left(\mathrm{m}^{3} / \mathrm{s}\right), C_{i}$ is the flow difference during the $i$ time period in the flow meter, and $a$ is the net port area of active gear $\left(\mathrm{m}^{2}\right), 0.3$ is the constant of the flow meter, and $t$ is the time of collecting the fish larvae (s). $D i$ is the density of fish larvae collected during the $i$ time period (ind. $/ \mathrm{m}^{3}$ ) and $\mathrm{Ni}$ is the number of fish larvae collected in the $i$ time period (ind.).

The coefficient of comparison is between the average density of fertilized eggs in the sampling section and the density of fertilized eggs in fixed point. $C=\sum \frac{\bar{d}}{d_{i}}$, where $d i$ is the fish fry density at fixed sampling points and $\bar{d}$ is the average density of the fish fry at each sampling site in the cross-section.

Fertilized eggs runoff during collection period is $M_{i}=D_{i} \times$ $Q_{i} \times C_{i}$, where $M i$ is the number of eggs passing through the section of the river during the $i$ time period, $D i$ is the density of eggs collected during the $i$ time period, and $Q i$ is the cross-section flow during the $i$ time of collection.

Fertilized eggs runoff during non-collection period is $M_{i+1}=\left(M_{i} / t_{i}+M_{i+1} / t_{i+1}\right) t_{i+1} / 2$, where $M i, i+1$ is the fertilized eggs runoff during collection interval of the $i, i+1$ time and $t i, i+1$ is the collection time interval of the $i, i+1$ time period. The total runoff of eggs collected in the river section is $M=$ $\sum M_{i}+\sum M_{i, i+1}$.

\section{Data Processing and Analysis}

The density of fish larvae was calculated as the fish larvae number per $100 \mathrm{~m}^{3}$ of the filtered water. The detrended correspondence analysis (DCA) and distance-based redundancy analysis (dbRDA) (length of gradient $<3$, suit for lineal model, otherwise using unimodal model) were used to unravel the variables explaining the differences in larval fish assemblages (Pan et al., 2015). Statistical significance was set at $P=0.05$. GAM was used to analyze hydrological factors on the abundance of fish larvae

${ }^{1}$ www.cjh.com.cn
(Daskalov, 1999). The smoothing splines (cubic spline) were used to represent the non-linear effect of predictors. The maximum degree of smoothing was set at 6 to avoid unrealistic patterns in the explanatory variables and to reduce over-fitting. According to the Akaike information criterion (AIC), the optimal number of nodes and the optimal model are determined (Akaike, 1973). As the original data are relatively discrete, the larval fish density and water environmental factors are processed using $\log (x+1)$ to meet the normal distribution of the analyzed data and using Monte-Carlo permutation test to sieve environmental factors (Pan et al., 2015). SPSS 19.0 and Excel 2016 were used for data analysis and drawing graphs, and Pearson correlation test was used for correlation analysis.

\section{Ethical Statement}

All sampling procedures were reviewed and approved according to the Regulations for the Administration of Affairs Concerning Experimental Animals, as approved and authorized by the State Council of the People's Republic of China.

\section{RESULTS}

\section{Adult Silver Carp Resources in the Lower Reach of the Yangtze River}

During the survey period from 2016 to 2019, according to the annual average CPUE in each river section, results showed that the annual average catch weight, the average annual catch number, and the $\mathrm{BL}$ range in the $\mathrm{HK}, \mathrm{AQ}, \mathrm{DT}$, and CS sections were different (Table 1). Further analysis showed that the BL range of silver carp in the lower reach of the Yangtze River was $31.9-876 \mathrm{~mm}$, and the average $\mathrm{BL}$ was $283.52 \mathrm{~mm}$, of which 100-300 mm was the dominant BL group, accounting for $51.27 \%$. The weight range of silver carp is $65.02-6,500 \mathrm{~g}$, and the average weight is $700.99 \mathrm{~g}$, of which $200-400 \mathrm{~g}$ group is the dominant weight group, accounting for $57.89 \%$, and the average weight is $387.61 \mathrm{~g}$ (Figure 2).

The cumulative fishing mortality, annual total resources, and annual total tail of silver carp in HK, AQ, DT, and CS show significant river section differences (Table 2). The cumulative mortality of fishing in the HK section is significantly lower than that in other sections, and the difference between the other three river sections is not obvious. The average annual fishery resources and tail in each river section are $\mathrm{CS}>\mathrm{DT}>\mathrm{HK}>$ AQ. Interestingly, the total fishery resources of CS section are significantly higher than those of other sections. 

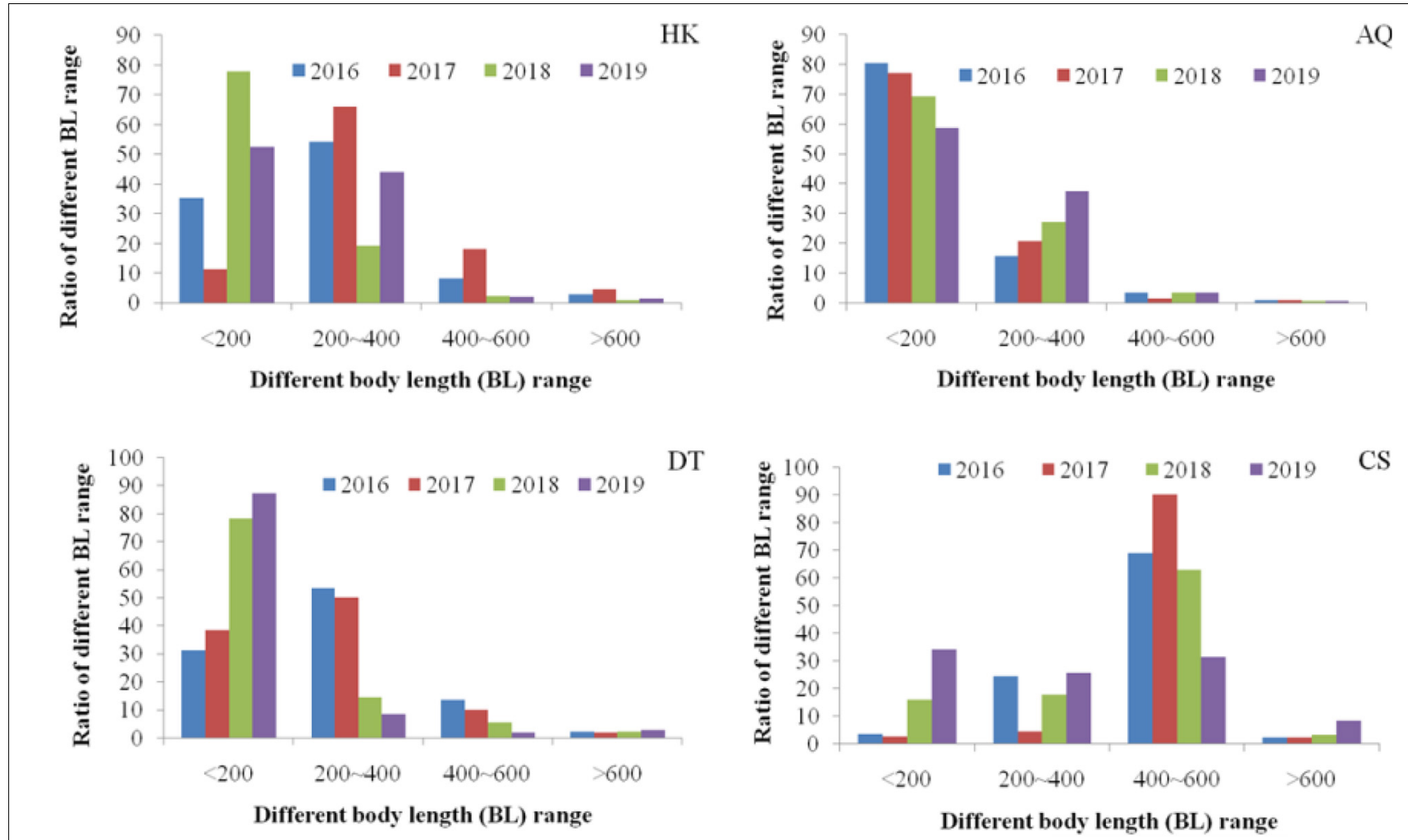

FIGURE 2 | Body weight range ratio in different sections.

\section{Fish Larvae of Silver Carp in the Lower Reach of the Yangtze River}

A total of 1,139 silver carp larvae were collected during 226 days of field survey in HK section from 2016 to 2019. A total of 224 fertilized eggs were collected at different stages, including tail bud-emergence stage, blast cyst stage, and early gastrula stage. During the investigation period, the fish larvae and fertilized eggs of silver carp showed an increasing trend year by year. According to above mentioned methods, the estimated runoff of silver carp in the early life history passing through the $\mathrm{HK}$ section from 2016 to 2019 is $5.08 \times 10^{8}, 5.69 \times 10^{8}, 6.72$ $\times 10^{8}$, and $7.32 \times 10^{8}$, respectively. A total of 826 silver carp larvae and 126 fertilized eggs were collected, from 2016 to 2019, during 312 days of field survey in the AQ section. During the investigation period, the variation of fish larvae and fertilized eggs of silver carp showed a fluctuating trend annually. According to the number of larvae and fertilized eggs collected, the runoff of

TABLE 2 | Total resources and catch tail of the sliver carp.

\begin{tabular}{lccc}
\hline Sections & $\begin{array}{c}\text { The cumulative } \\
\text { fishing mortality (\%) }\end{array}$ & $\begin{array}{c}\text { Annual total } \\
\text { resources(t) }\end{array}$ & $\begin{array}{c}\text { Annual total tail } \\
\text { (tail) }\end{array}$ \\
\hline HK & 4.11 & 371.74 & 102,604 \\
AQ & 6.72 & 235.22 & 83,978 \\
DT & 5.77 & 640.69 & 66,973 \\
CS & 5.51 & 2612.65 & 226,142
\end{tabular}

silver carp larvae passing through the AQ section from 2016 to 2019 is estimated to be $8.08 \times 10^{8}, 9.69 \times 10^{8}, 9.72 \times 10^{8}$, and $10.32 \times 10^{8}$, respectively. However, only 36 silver carp larvae and 2 fertilized eggs were collected during 236 days of field survey in DT and CS sections during the investigation period. By the same estimating method, the runoff passing through the DT and CS sections can be ignored.

\section{Distribution Patterns of the Adult Fish}

During the investigation period, different BL groups of silver carp showed different distribution patterns in the sampled sections (Figure 2). Silver carps of different BL groups in the HK section showed a downward trend year by year. The juvenile silver carp in the below $200 \mathrm{~mm}$ BL group in the AQ section were significantly higher than those in other BL groups and showed a downward trend year by year. The silver carp in the $200-400 \mathrm{~mm}$ BL group showed an upward trend yearly, and the interannual distribution in the 400-600 $\mathrm{mm}$ and above $600 \mathrm{~mm}$ BL groups has no significant difference. The ratio of juvenile silver carp in the below $200 \mathrm{~mm}$ BL group in the DT section showed an obvious upward trend year by year, while the 200-400 and 400-600 mm $\mathrm{BL}$ groups showed a downward trend. The ratio of juvenile silver carp in the below $200 \mathrm{~mm}$ BL group and adult silver carp in the above $600 \mathrm{~mm} \mathrm{BL}$ group in the CS river section is small and showed an obvious upward trend year by year. The $400-600 \mathrm{~mm}$ $\mathrm{BL}$ group has an absolute advantage in the surveyed section, but the resources showed a downward trend year by year. 
Silver carp of different BL groups also have obvious seasonal differences between the investigated sections. Seasonal variations in the adult fish in different sections are shown in Figure 3. During spring, autumn, and winter, the above $600 \mathrm{~mm}$ BL group of silver carp in the CS section was significantly higher than that in other sections. The $400-600 \mathrm{~mm}$ BL group in each section in summer was obviously high. In autumn, the silver carp in the below $200 \mathrm{~mm} \mathrm{BL}$ group was dominant in the HK, AQ, and DT sections, but the ratio in the CS section was lowest. In winter, the ratio of juvenile silver carp in the HK and AQ sections in the below $200 \mathrm{~mm} \mathrm{BL}$ group was high, and the proportion of adult silver carp (400-600 mm and $>600 \mathrm{~mm}$ BL group) in the DT and CS sections was high. The results showed that in the river-lake connected sections such as $\mathrm{HK}$ and $\mathrm{AQ}$, the proportion of juvenile silver carp in the below $200 \mathrm{~mm}$ BL group was significantly higher than that in other investigated sections.

\section{Change Patterns of the Larval Fish and Influential Factors}

During the survey time, as for the larval fish results, the highest abundance of larval fish and fertilized eggs appeared in the HK and $\mathrm{AQ}$ sections. Comparing the average abundance of larval fish in each sampling section exhibited the trend as $\mathrm{HK}>\mathrm{AQ}>>$ DT $>$ CS. Interestingly, the highest abundance of the larval fish appeared in the HK section, and the lowest abundance appeared in the CS section, which was almost never sampled. Furthermore, the larval fish and fertilized eggs were continuously sampled from early June to early August, and peaked in early July. The GAM results showed that the hydrological factors significantly influence the abundance of fish larvae (Figure 4; $P<0.05$ ). In the HK and AQ sections, the contribution orders were the daily increasing rate of water level, WTP, water temperature, and the daily increasing rate of discharge (Table 3, $P<0.05$ ). Among them, the total deviation interpretation rate by the optimized GAM was 67.2 and $83.7 \%$, respectively. Results revealed the concrete influence of hydrological conditions on the abundance of the larval carps (Figure 4).

\section{DISCUSSION}

\section{Importance of Adult Silver Carp and Early Resource Research}

The silver carp is a type of semi-migratory fish species between rivers and lakes, and it grows up, matures in floodplain lakes, and spawns in rivers (often triggered by increasing temperature and rising water levels). Due to overfishing, water pollution, habitat loss, and hydroelectric engineering such as the TGD, the natural resources of the four Chinese carps have declined considerably during the past decades. Studies showed that the closer to the dam, the more obvious the effect is. Most studies on the complementary mechanism of the silver carp focused in the up and middle reaches, and the lower reach of the Yangtze River has often been ignored. Some studies have indicated that the recruit population contribution has shifted from the middle reaches

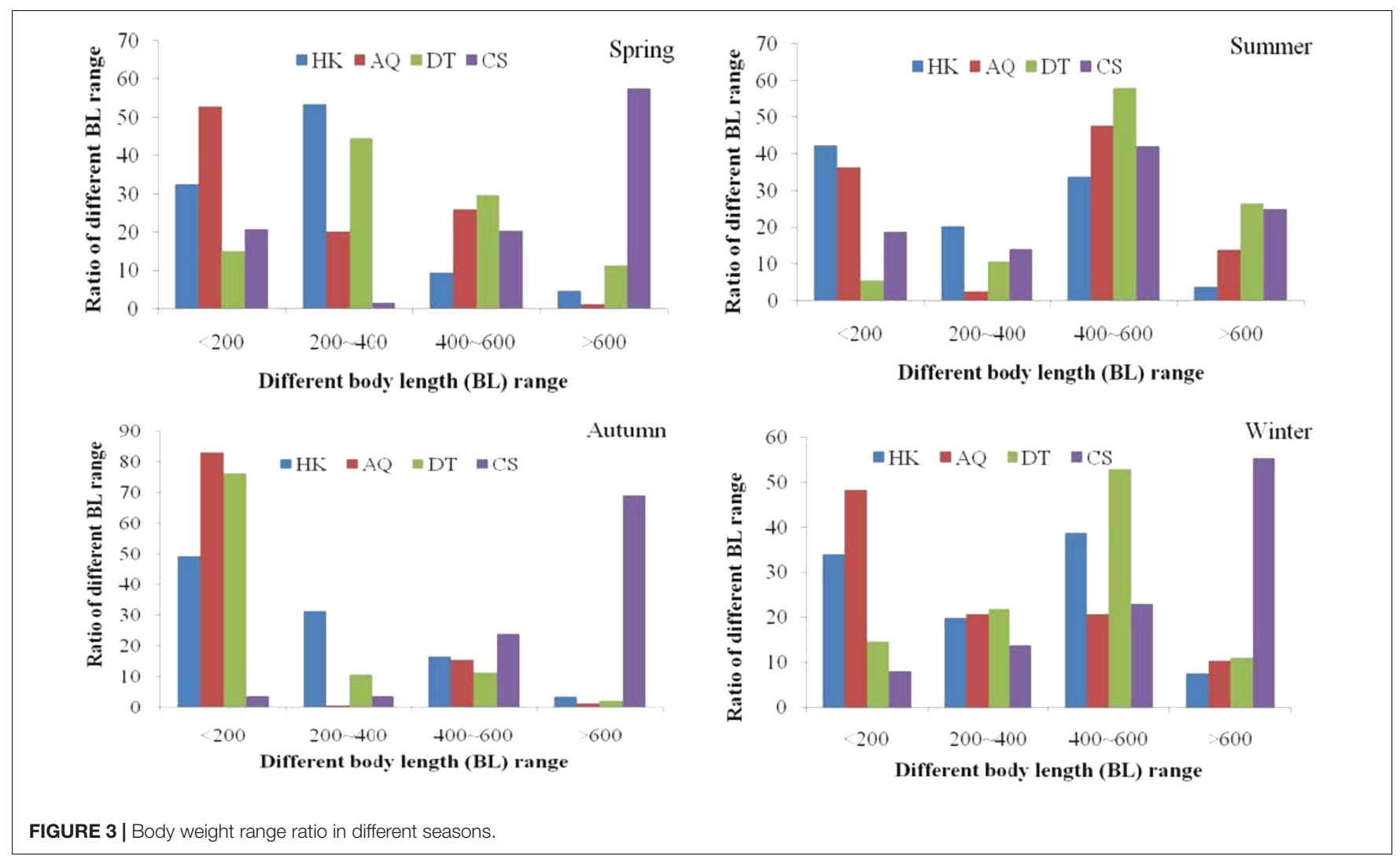



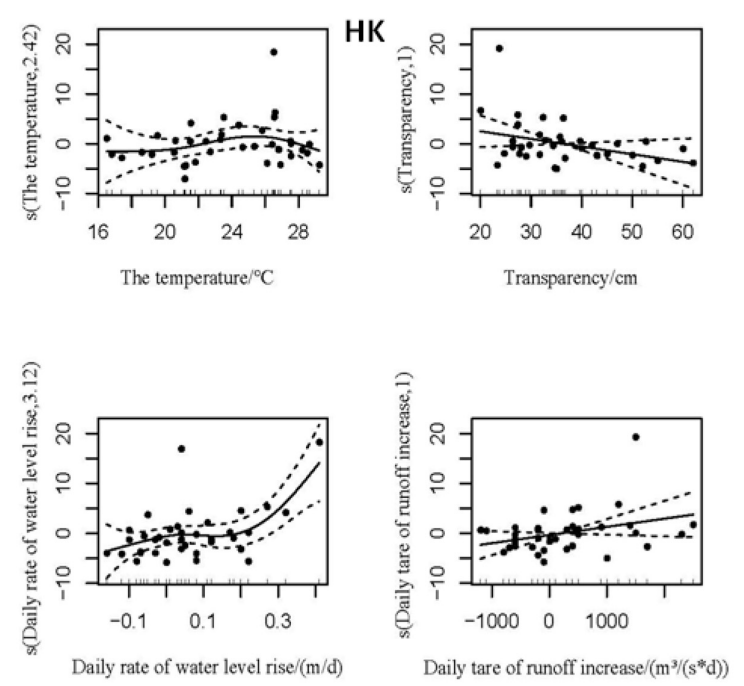
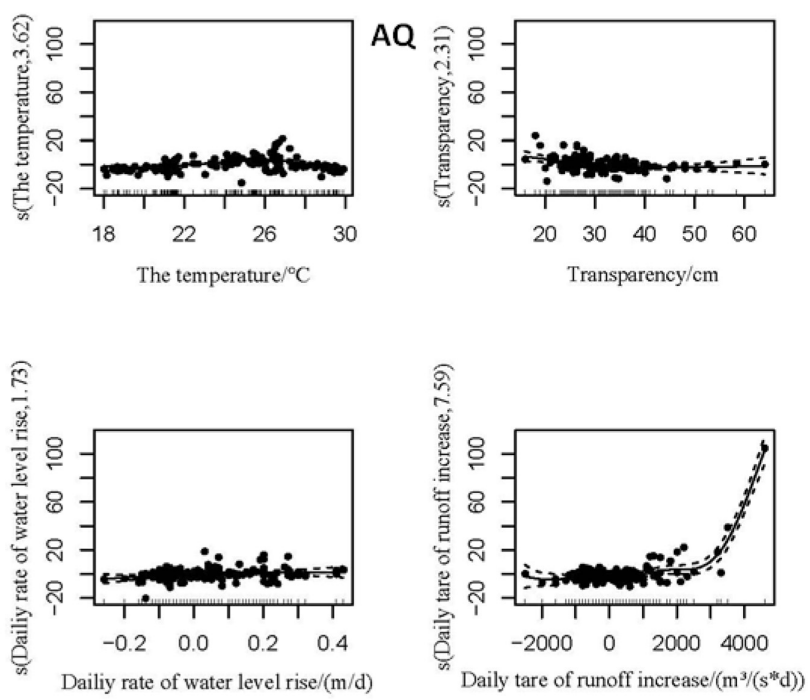

FIGURE 4 | GAM analyses for fish larvae in the HK and AQ sections. The ordinate $\mathrm{s}($ ) indicates the non-parametric smoothing term, and the abscissa indicates the parameter value. The solid line indicates the regression curve obtained by automatically determining the smoothing parameters, and the dotted line represents the possible variation range of the regression curve.

TABLE 3 | Deviation interpretation rate of environmental factors for the GAM model.

\begin{tabular}{|c|c|c|c|c|c|}
\hline $\begin{array}{l}\text { Dependent variable } \\
\text { (Ichthyoplankton density) }\end{array}$ & Water temperature & Water transparency & Water level & Water runoff & $\begin{array}{l}\text { Total deviation interpretation } \\
\text { rate }\end{array}$ \\
\hline HK & $27.6 \%$ & $49.5 \%$ & $49.6 \%$ & $29.4 \%$ & $67.2 \%$ \\
\hline$A Q$ & $16.8 \%$ & $26.3 \%$ & $31.6 \%$ & $74.2 \%$ & $83.7 \%$ \\
\hline DT & - & - & - & - & - \\
\hline CS & - & - & - & - & - \\
\hline
\end{tabular}

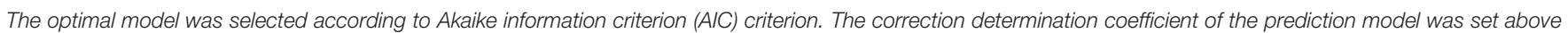

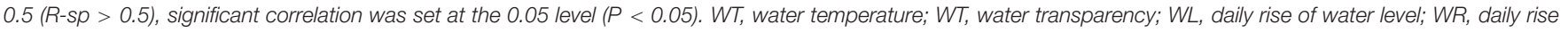
of water runoff.

to the lower reaches. In this case, studies on the complement mechanism of the silver carp in the lower reach of the Yangtze River became even more important. Furthermore, the hatching of fertilized eggs and the development of fish larvae were transferred by the downstream drift and subsequently juvenile fish were moved into nursery areas and grown up, and such biological process probably happens in the lower reaches. For this reason, clarifying the growth and death characteristics of silver carp in the early life stage and its supplementary contribution to the adult population will provide a scientific and basic data support for the protection of silver carp resources in the Yangtze River.

\section{Habitat Characteristics and Resource Distribution}

The field survey results showed that the closer the section is to the estuary, the fewer the larvae silver carp is, and the bigger BL group gradually increased. Adult silver carps can swim freely and have strong control ability in water. What is more, the adult silver carps tend to choose habitats with slow water flow, rich biological bait, and less human interference. In the lower reach of the Yangtze River from HK to the estuary, there are many sandbars, developed water network, distributed thousands of bays, and rich bait biological sources along the river. This kind of habitat is an important feeding ground for the silver carp (Shuai et al., 2018). Results in this study found that adult silver carps were widely distributed in the investigated sections. In the section with sandbar habitat, such as HK, AQ, DT, and CS, the distribution density of the adult fish was high, and the distribution of $\mathrm{BL}$ group was rich. Interestingly, the adult silver carp resources are highest in the CS section. The CS section is wide, with obvious river diversion, and has the characteristics of rising and falling tides. Some studies have shown that the tide can significantly promote the enrichment of plankton, which are the main feed resource for the silver carps. Therefore, comparing with other sections, the CS section has more abundant bait organisms and is more suitable for the fish growth. Another important reason for more big silver carps in this section may be the numerous and effective stock enhancement in the lower reaches of the Yangtze River in recent years.

The spatial heterogeneity of the fish larvae is mainly affected by the hydrological situation and the topography of the water area. The sandbars obviously existed in the HK and AQ sections and divided water flow into two or more streams. This habitat 
usually can form the "vortex water," which is necessary for the silver carp spawning behavior. Based on the study result, it can be speculated that the spawning ground are distributed in Jiangzhou, Longping, and Qizhou waters, which contain many sandbars, with eddies or bends in the river center (unpublished data). There is no spawning ground found below AQ section. The main reason is that after silver carp spawning, the life history stages of drifting and first feed must be completed in the early development stage; the drifting distance from AQ to the estuary cannot meet the developmental needs of the silver carp from the fertilized eggs to the initial feed stage (Shuai et al., 2018). The HK section is connected to the Poyang Lake, which is the river-lake connected section in the lower reach of the Yangtze River, and the AQ section is a relatively stable bifurcated river with many complex beaches. This complex ecosystem with the characteristics of connecting river and lake (RL) can provide good nursing and feeding places for silver carps.

\section{Spatial-Temporal Dynamics and Affecting Factors}

Silver carp has the migratory habit between river and its connected water body, and its distribution pattern has obviously seasonal differences (Zhang et al., 2021). Because the adult fish may choose the complex section for winter migration, in spring, it was found that the ratio of the adult fish with a lower BL was higher in the HK and AQ sections. Summer is the spawning season, the WT and the WL begin to rise in the river, and under the accelerating current, the adult fish begin spawning. For this reason, the number of middle and high $\mathrm{BL}$ groups increased generally in the HK and AQ sections. After the spawning period, the hatched fish larvae successively entered Poyang Lake or Wanhe River for nursing and feeding. However, the CS section has a little salinity and is not fit for the hatched fish larvae. Therefore, the ratio of the below $200 \mathrm{~mm}$ BL group was lowest in the CS section. It can be seen that the seasonal distribution characteristics of adult silver carp are closely related to their reproductive biological characteristics and river-specific habitat.

Drifting development extensively exists in the early stage of river fish species, and its growth and development is also affected by abiotic and biological factors (Nagrodski et al., 2012). Abiotic factors include WL, riverbed shape, WT, and hydrological conditions. Biological factors include fish development stage, habitat preference, and interspecific relationship (Jager and DeAngelis, 2018). The temporal dynamics of the silver carp in the early life history stage can directly reflect the varying characteristics of the adult fish spawning time. The WT for the silver carp spawning is generally required to be above $18^{\circ} \mathrm{C}$; in this study, the fish eggs in the HK section were investigated from late May to mid-July, and the WT fluctuated in the range of $20.4-28.7^{\circ} \mathrm{C}$. In the fish spawning season, the changes in river hydrology, such as the increase of water flow, the rise of water level, and the acceleration of river flow velocity, are important and essential factors causing the spawning peak of the fish (Zhang et al., 2021). In 2019, the runoff and WL began to rise in late May and remained high until the middle of July, which induced three fish egg peaks in the HK and AQ sections. Related studies have shown that WT, WF, and WTP were essential environmental factors affecting the community structure of fish larvae (Machado et al., 2017). Furthermore, the GAM results showed that the hydrological factors have the different contribution rate to the abundance of fish larvae, which was in accordance with the reproductive biology of the silver carp (Kun et al., 2019).

When analyzing the spatial distribution of fish larvae abundance in the HK and AQ sections, it is found that the fertilized eggs were collected in the three sites except the Waterway of Poyang Lake in the HK section. It can be inferred that the supplement population of silver carp only came from the upstream section of the Yangtze River. Due to the different natural conditions such as riverbed shape, river flow velocity, and watershed dynamics between various sites in the section, the drift density of fish larvae varied greatly between different sites on the same river section. Interestingly, the egg density in the river center is significantly higher than that on both banks, which is consistent with the biological characteristics of silver carp egg development and drifting (Wang et al., 2019).

\section{Possible Complementary Mechanism}

Understanding the complementary mechanisms is critical to the effective conservation of wild fish populations (Goldenberg et al., 2019). There were numerous evidences that qualified relationships existed between hydrology and density of fish larvae (Doyle et al., 2002; Jenkins et al., 2015). When a natural flood with water velocity $\geq 0.7 \mathrm{~m} / \mathrm{s}$ occurred in the Mississippi River, it can stimulate the sliver carp spawning behavior (Shuai et al., 2018). The project of biological regulation from TGD also can lead hydrological changes and stimulate the silver carp to spawn in the spawning season (Zhang et al., 2021). Unfortunately, it has been proven by field surveys that the construction of TGD had a dramatic influence on the abundance of silver carp larvae (Zhang et al., 2020). Dams in the Yangtze River have modified water hydrology and flow and then affected the silver carp migration and reproduction (Fu et al., 2003). Because the lower reaches of the Yangtze River are far away from the TGD, the hydrological characteristics are less affected (Doyle et al., 2002). Furthermore, the connectivity between Poyang Lake and the Yangtze River is conducive to the fish reproduction. The RL ecosystem forms the reason for the adult amount of resources of silver carp in the surveyed sections. Furthermore, the most suitable discharge of spawning habitats of silver carp in the Yangtze River were $15,000-21,300 \mathrm{~m}^{3} / \mathrm{s}$ (Yu et al., 2018). Due to the inflow of tributaries along the river, this is a kind of essential topographic habitat for forming the bubble water (Shuai et al., 2018). In this water area, the adult sliver carp spawned and the fish in early life history stages developed. However, the complementary quantity and quality derived from the adult population absolutely depends on the parent fish. How many parent fish lived in the Yangtze River and whether they can spawn successfully should be considered systematically. Therefore, continuous field surveys on larvae and adult fish resources in the whole Yangtze River Basin and exploring the complementary relationship will be considered persistently.

Although only 4 years of systematic data were included in this study, we proposed that the adult silver carp has the distinctive preference in the habitat selection. Furthermore, being 
the overfishing in the Yangtze River, the adult fish that can spawn in the spawning period all come from the up reach of the river, and downstream fish have less complement contribution to the larval fish population. In contrast, it is also found that the river flows, such as discharge, artificial flood, or flood pulses, are factors that effectively determined larval fish abundance in the Yangtze River. Based on the above results, we can propose an exchange regulating method that the parent fish can intercourse each other between the upstream and downstream reaches in the Yangtze River during their breeding season. By doing these, their population, perhaps, expands quickly and their breeding population can recover in the future, and it would be a preferable method to control the propagation of silver carps (Ban et al., 2019; Wang et al., 2019). Our study provides preliminary clues to understand how the adult silver carps recruit and migrate between sections along the Yangtze River. Besides, understanding the breeding characteristics of the silver carps in their native range and their protecting biography are also of great significance. Future research will focus on the detail complementary mechanism silver carp both in the natural habitat and invasion waters.

\section{Occurrence Trend and Protection Suggestions}

This study has carried out research on the temporal and spatial dynamics of adult and early resources of silver carps and analyzed the supplementary contribution of early resources in different sections of the lower reaches of the Yangtze River to adult populations. The research results provided theoretical support for the formulation of fishery resources conservation and management measures in the Yangtze River. The accumulation of these basic data can also provide a scientific basis for resource evaluation and species protection strategies of silver carps in the Yangtze River. Poyang Lake has typical habitat characteristics of connecting rivers and lakes; it is the key ecosystem to maintain the successful supplement of silver carp early resources to adult fish resources. However, how to ensure the connectivity of the $\mathrm{RL}$ effectively, so as to enhance the silver carp resources in the Yangtze River, should be focused on especially. Therefore, wading projects such as sand mining, shipping, and aquatic operations in

\section{REFERENCES}

Addy, S., and Wilkinson, M. E. (2021). Embankment lowering and natural selfrecovery improves river-floodplain hydro-geomorphic connectivity of a gravel bed river. Sci. Total Environ. 770:144626. doi: 10.1016/j.scitotenv.2020.144626

Akaike, H. (1973). Information Theory and an Extension of the Maximum Likelihood Principle. Germany: Springer. 267-281.

Ban, X., Diplas, P., Shih, W., Pan, B., Xiao, F., and Yun, D. (2019). Impact of Three Gorges Dam operation on the spawning success of four major Chinese carps. Ecol. Eng. 127, 268-275. doi: 10.1016/j.ecoleng.2018.12.004

Cao, W., Chang, J., Qiao, Y., and Duan, Z. (2007). Fish Resources of Early Life History Stages in Yangtze River. Beijing: China Water Power Press.

Chen, T., Wang, Y., Gardner, C., and Wu, F. (2020). Threats and protection policies of the aquatic biodiversity in the Yangtze River. J. Nat. Conserv. 58:125931. doi: 10.1016/j.jnc.2020.125931

Chen, Y., Zhang, S., Huang, D., Li, B.-L., Liu, J., Liu, W., et al. (2017). The development of China's Yangtze River Economic Belt: how to make it in a green way? Sci. Bull. 62, 648-651. doi: 10.1016/j.scib.2017.04.009 silver carp migration channels, spawning grounds, and feeding grounds must be prohibited during the spawning period. At the same time, the correlation analysis between adult and fish larvae resources of silver carp is conducive to clarify the complementary mechanism. In short, establishing a reliable biological data and explaining the supplementary contribution of early resources to adult resources will be the key content of later research.

\section{DATA AVAILABILITY STATEMENT}

The original contributions presented in the study are included in the article/supplementary material, further inquiries can be directed to the corresponding author/s.

\section{ETHICS STATEMENT}

All sampling procedures involving animals were reviewed and approved by the Regulations for the Administration of Affairs Concerning Experimental Animals and approved and authorized by the State Council of People's Republic of China.

\section{AUTHOR CONTRIBUTIONS}

D-AF was responsible for data scoring and analysis, and writing the manuscript. D-PX conceived and designed the experiments. Y-FZ, PR, X-PX, Y-XP, and LR helped selecting the icythyoplankton sample, survey work, and data analysis during manuscript preparation. All authors have read and approved the final manuscript.

\section{FUNDING}

This study was supported by the National Key Research and Development Program of China (2018YFD0900903) and the National Infrastructure of Fishery Germplasm Resources (2021DKA3047003).

Cheng, F., Li, W., Wu, Q., Murphy, B., and Xie, S. (2013). MOTU analysis of ichthyoplankton biodiversity in the upper Yangtze River. China. J. Appl. Ichthyol. 29, 872-876. doi: 10.1111/jai.12207

Daskalov, G. (1999). Relating fish recruitment to stock biomass and physical environment in the Black Sea using generalized additive models. Fish. Res. 41, 1-23. doi: 10.1016/s0165-7836(99)00006-5

Doyle, M. J., Mier, K. L., Busby, M. S., and Brodeur, R. D. (2002). Regional variation in springtime ichthyoplankton assemblages in the northeast Pacific Ocean. Progr. Oceanogr. 53, 247-281. doi: 10.1016/s0079-6611(02)00033-2

Fang, D. A., Luo, Y. T., Xu, D. P., Yang, X. W., and Wang, X. H. (2021). Relationship between genetic risk and stock enhancement of the silver carp (Hypophthalmichthys molitrix) in the Yangtze River. Fish. Res. 235:105829. doi: 10.1016/j.fishres.2020.105829

Fu, C., Wu, J., Chen, J., Wu, Q., and Lei, G. (2003). Freshwater fish biodiversity in the Yangtze River basin of China: patterns, threats and conservation. Biodivers. Conserv. 12, 1649-1685.

Goldenberg, S. Z., Owen, M. A., Brown, J. L., Wittemyer, G., Oo, Z. M., and Leimgruber, P. (2019). Increasing conservation translocation success by 
building social functionality in released populations. Global Ecol. Conserv. 18:e00604. doi: 10.1016/j.gecco.2019.e00604

Huang, M., Ding, L., Wang, J., Ding, C., and Tao, J. (2021). The impacts of climate change on fish growth: a summary of conducted studies and current knowledge. Ecol. Indicat. 121:106976. doi: 10.1016/j.ecolind.2020.106976

Jager, H. I., and DeAngelis, D. L. (2018). The confluences of ideas leading to, and the flow of ideas emerging from, individual-based modeling of riverine fishes. Ecol. Model. 384, 341-352. doi: 10.1016/j.ecolmodel.2018.06.013

Jenkins, G. P., Kenner, T., Brown, A., and Coleman, R. (2015). Fish assemblages in locations with alternative structured habitats in an eelgrass, Zostera, dominated bay: biodiversity value and potential for refuge. Estuar. Coast. Shelf Sci. 161, 25-37. doi: 10.1016/j.ecss.2015.05.007

Kun, Z., Fangyuan, J., Huan, C., Tafa, D. D., Qili, W., and Zhongze, Z. (2019). Temporal and spatial variations in zooplankton communities in relation to environmental factors in four floodplain lakes located in the middle reach of the Yangtze River, China. Environ. Poll. 251, 277-284. doi: 10.1016/j.envpol.2019. 04.139

Li, S. F., Cai, Z. W., Lu, W. M., He, X., and Zhao, R. P. (1984). On the growth rate of Silver carps from different sources of Changjiang River and Zhujiang River. J. Fish. China 8, 211-218.

Liu, S. P., Chen, D. Q., Duan, X. B., Qiu, S. L., and Huang, M. J. (2004). Monitoring of the Four Famous Chinese Carps resources in the middle and upper reaches of the Yangtze River. Resour. Environ. Yangtze Basin 13, $84-87$.

Liu, X., Qin, J., Xu, Y., Ouyang, S., and Wu, X. (2019). Biodiversity decline of fish assemblages after the impoundment of the Three Gorges Dam in the Yangtze River Basin, China. Rev. Fish Biol. Fish. 29, 177-195. doi: 10.1007/s11160-01909548-0

Machado, I., Calliari, D., Denicola, A., and Rodríguez-Graña, L. (2017). Coupling suitable prey field to in situ fish larval condition and abundance in a subtropical estuary. Estuar. Coast. Shelf Sci. 187, 31-42. doi: 10.1016/j.ecss.2016.12.021

Nagrodski, A., Raby, G. D., Hasler, C. T., Taylor, M. K., and Cooke, S. J. (2012). Fish stranding in freshwater systems: sources, consequences, and mitigation. J. Environ. Manag. 103, 133-141. doi: 10.1016/j.jenvman.2012.03. 007

Pan, B. Z., Wang, H. Z., Ban, X., and Yin, X. A. (2015). An exploratory analysis of ecological water requirements of macroinvertebrates in the Wuhan branch of the Yangtze River. Quatern. Int. 38, 256-261. doi: 10.1016/j.quaint.2014.10. 011

Ren, P., He, H., Song, Y., Cheng, F., and Xie, S. (2016). The spatial pattern of larval fish assemblages in the lower reach of the Yangtze River: potential influences of river-lake connectivity and tidal intrusion. Hydrobiologia 766, 365-379. doi: 10.1007/s10750-015-2471-2

Rodriguez-Dominguez, A., Connell, S. D., Leung, J. Y. S., and Nagelkerken, I. (2019). Adaptive responses of fishes to climate change: feedback between physiology and behaviour. Sci. Total Environ. 692, 1242-1249. doi: 10.1016/j. scitotenv.2019.07.226

Rogers, T. A., Fowler, A. J., Steer, M. A., and Gillanders, B. M. (2019). Spatial connectivity during the early life history of a temperate marine fish inferred from otolith microstructure and geochemistry. Estuar. Coast. Shelf Sci. 227:106342. doi: 10.1016/j.ecss.2019.106342

Schmidt, H., Radinger, J., Teschlade, D., and Stoll, S. (2020). The role of spatial units in modelling freshwater fish distributions: comparing a subcatchment and river network approach using MaxEnt. Ecol. Model. 418:108937. doi: 10.1016/j. ecolmodel.2020.108937

Servili, A., Canario, A. V. M., Mouchel, O., and Muñoz-Cueto, J. A. (2020). Climate change impacts on fish reproduction are mediated at multiple levels of the brain-pituitary-gonad axis. Gener. Compar. Endocrinol. 291:113439. doi: 10.1016/j.ygcen.2020.113439

Shuai, F., Lek, S., Baehr, C., Park, Y.-S., Li, Y., and Li, X. (2018). Silver carp larva abundance in response to river flow rate revealed by cross-wavelet modelling. Ecol. Model. 383, 98-105. doi: 10.1016/j.ecolmodel.2018.05.020
Sokta, L., Jiang, T., Liu, H., Xuan, Z., Qui, C., Chen, X., et al. (2020). Loss of Coilia nasus habitats in Chinese freshwater lakes: an otolith microchemistry assessment. Heliyon 6:e04571. doi: 10.1016/j.heliyon.2020. e04571

Song, Y., Cheng, F., Ren, P., Wang, Z., and Xie, S. (2019). Longitudinal recovery gradients of drifting larval fish assemblages in the middle reach of the Yangtze River: impact of the Three Gorges Dam and conservation implementation. Can. J. Fish. Aquat. Sci. 76, 2256-2267. doi: 10.1139/cjfas-2018-0409

Tao, J., Yang, Z., Cai, Y., Wang, X., and Chang, J. (2017). Spatiotemporal response of pelagic fish aggregations in their spawning grounds of middle Yangtze to the flood process optimized by the Three Gorges Reservoir operation. Ecol. Eng. 103, 86-94. doi: 10.1016/j.ecoleng.2017.03.002

van Vliet, M. T. H., Franssen, W. H. P., Yearsley, J. R., Ludwig, F., Haddeland, I., Lettenmaier, D., et al. (2013). Global river discharge and water temperature under climate change. Glob. Environ. Change 23, 450-464. doi: 10.1016/j. gloenvcha.2012.11.002

Wang, Y., Kao, Y.-C., Zhou, Y., Zhang, H., Yu, X., and Lei, G. (2019). Can water level management, stock enhancement, and fishery restriction offset negative effects of hydrological changes on the four major Chinese carps in China's largest freshwater lake? Ecol. Model. 403, 1-10. doi: 10.1016/j.ecolmodel.2019. 03.020

Yao, W., Rutschmann, P., and Sudeep. (2015). Three high flow experiment releases from Glen Canyon Dam on rainbow trout and flannelmouth sucker habitat in Colorado River. Ecol. Eng. 75, 278-290.

Yu, L., Lin, J., Chen, D., Duan, X., Peng, Q., and Liu, S. (2018). Ecological Flow Assessment to Improve the Spawning Habitat for the Four Major Species of Carp of the Yangtze River: a Study on Habitat Suitability Based on Ultrasonic Telemetry. Water 10:600. doi: 10.3390/w10050600

Yue, Y., Yan, D., Yue, Q., Ji, G., and Wang, Z. (2021). Future changes in precipitation and temperature over the Yangtze River Basin in China based on CMIP6 GCMs. Atmospher. Res. 264:105828. doi: 10.1016/j.atmosres.2021. 105828

Zandalinas, S. I., Fritschi, F. B., and Mittler, R. (2021). Global Warming, Climate Change, and Environmental Pollution: recipe for a Multifactorial Stress Combination Disaster. Trends Plant Sci. 26, 588-599. doi: 10.1016/j.tplants. 2021.02.011

Zhang, P., Qiao, Y., Grenouillet, G., Lek, S., Cai, L., and Chang, J. (2021). Responses of spawning thermal suitability to climate change and hydropower operation for typical fishes below the Three Gorges Dam. Ecol. Indicat. 121:107186. doi: 10.1016/j.ecolind.2020.107186

Zhang, P., Qiao, Y., Jin, Y., Lek, S., Yan, T., He, Z., et al. (2020). Upstream migration of fishes downstream of an under-construction hydroelectric dam and implications for the operation of fish passage facilities. Glob. Ecol. Conserv. 23:e01143. doi: 10.1016/j.gecco.2020.e01143

Conflict of Interest: The authors declare that the research was conducted in the absence of any commercial or financial relationships that could be construed as a potential conflict of interest.

Publisher's Note: All claims expressed in this article are solely those of the authors and do not necessarily represent those of their affiliated organizations, or those of the publisher, the editors and the reviewers. Any product that may be evaluated in this article, or claim that may be made by its manufacturer, is not guaranteed or endorsed by the publisher.

Copyright (c) 2022 Fang, Zhou, Ren, Peng, Xue, Ren and Xu. This is an openaccess article distributed under the terms of the Creative Commons Attribution License (CC BY). The use, distribution or reproduction in other forums is permitted, provided the original author(s) and the copyright owner(s) are credited and that the original publication in this journal is cited, in accordance with accepted academic practice. No use, distribution or reproduction is permitted which does not comply with these terms. 